\title{
УДК $537.8+550.84$ \\ ФИЗИКО-ХИМИЧЕСКИЕ СВОЙСТВА НЕФТИ МЕСТОРОЖДЕНИЙ ВОСТОЧНОЙ И ЗАПАДНОЙ СИБИРИ: КОМПЛЕКСНОЕ ИЗУЧЕНИЕ МЕТОДАМИ ДИЭЛЕКТРИЧЕСКОЙ СПЕКТРОСКОПИИ И ЯМР-РЕЛАКСОМЕТРИИ
}

\author{
Мезин Андрей Алексеевич1, \\ MezinAA@ipgg.sbras.ru \\ Шумскайте Мария Йоновна', \\ ShumskaiteMl@ipgg.sbras.ru \\ Чернова Елена Сергеевна², \\ ellenchernova@yandex.ru \\ Бурухина Александра Ильинична ${ }^{1}$, \\ BurukhinaAl@ipgg.sbras.ru \\ 1 Институт нефтегазовой геологии и геофизики им. А.А. Трофимука СО РАН, \\ Россия, 630090, г. Новосибирск, пр. Академика Коптюга, 3. \\ 2 Новосибирский государственноый университет, \\ Россия, 630090, г. Новосибирск, ул. Пирогова, 1.
}

\begin{abstract}
Актуальность работы обусловлена возрастающим интересом к комплексной интерпретации данных нескольких методов при определении петрофизических и фризико-химических свойств горных пород и внутрипластовых фрлюидов. Физикохимические свойства нефти определяются по данным комплекса методов диэлектрической спектроскопии, ЯМРрелаксометрии и геохимического анализа. Результаты этих методов дополняют друг друга, поскольку отличаются разной чувствительностью к определенным характеристикам породы и насьщающего ее фрюида.

Цель: совместная интерпретация данных методов диэлектрической спектроскопии и ЯМР-релаксометрии для определения группового состава и физико-химических свойств проб несрти, сопоставление с результатами геохимического анализа.

объекты: пробы нефтти и конденсатов месторождений Восточной и Западной Сибири, характеризующиеся разными фризикохимическими свойствами.

Методы: лабораторные методы диэлектрической спектроскопии, направленной на определение комплексной диэлектрической проницаемости; ЯМР-релаксометрии, позволяющей оценить групповой состав исследуемого фрлюида; стандартные геохимические методы, включающие определение фризико-химических свойств, фракционного и группового химического состава нефоти.

Результаты. Изучено 48 проб нефтей и конденсатов месторождений Восточной и Западной Сибири. Для 29 проб установлены значения: плотности при $20^{\circ} \mathrm{C}$, вязкости при 20 и $60{ }^{\circ} \mathrm{C}$, содержания температурных фракций выше и ниже $200{ }^{\circ} \mathrm{C}$, coдержания метано-нафтеновых и нафтено-ароматических углеводородов, смол и асфральтенов. Экспериментально установлена зависимость диэлектрической проницаемости и времени поперечной релаксации от содержания разных групп углеводородных соединений, которая показала высокую чувствительность применяемых в работе методов к содержанию смолистоассральтеновых соединений. Увеличение их доли в составе пробы нефрти приводит к существенному уменьшению времен поперечной релаксации и значительному увеличению значений диэлектрической проницаемости. По ЯМР-данным был определен групповой состав проб нефтии, который с точностью до $5 \%$ при температуре $25{ }^{\circ} \mathrm{C}$ согласуется с результатами геохимического анализа. Поскольку времена поперечной релаксации ароматических соединений и насыщенных углеводородов сильно перекрываются, это не позволяет более детально установить граничные времена поперечной релаксации для каждой группы углеводородных соединений.
\end{abstract}

Ключевые слова:

Групповой состав, диэлектрическая проницаемость, релаксационные характеристики, реологические свойства нефти, совместная интерпретация.

\section{Введение}

Одной из основных тенденций в развитии интерпретационной базы лабораторных исследований при определении петрофизических параметров горных пород и физико-химических свойств внутрипластовых флюидов является комплексирование данных методов, основанных на разных физических принципах. К таким методам можно отнести диэлектрическую спектроскопию и ЯМР-релаксометрию. В формировании диэлектрической проницаемости (ДП) образца большую роль играют поляризационные процессы на поверхности раздела фаз, при этом ядерно-магнитные свойства образца в значительной мере определяются процессами другого типа, действующими на тех же поверхностях. Разная чувствительность к определенным характеристикам породы и пластового флюида может дать дополнительную информацию об изучаемом объекте при комплексной интерпретации данных этих методов [1-4]. В табл. 1 приведена сравнительная чувствительность методов ядерно-магнитного резонанса (ЯМР) и многочастотных электромагнитных исследований (МЭИ). 
Таблица 1. Сравнительная чувствительность ЯМР и МЭИ [1]

Table 1. Comparative sensitivity of NMR and MES methods [1]

\begin{tabular}{|c|c|c|}
\hline $\begin{array}{c}\text { Характеристика } \\
\text { породы } \\
\text { Rock } \\
\text { characteristic }\end{array}$ & $\begin{array}{c}\text { Чувствительность } \\
\text { ЯMP } \\
\text { NRM sensitivity }\end{array}$ & $\begin{array}{c}\text { Чувствительность } \\
\text { МЭИ } \\
\text { MES sensitivity }\end{array}$ \\
\hline $\begin{array}{c}\text { Пористость } \\
\text { Porosity }\end{array}$ & $\begin{array}{c}\text { Высокая } \\
\text { High }\end{array}$ & $\begin{array}{c}\text { Высокая } \\
\text { (для водонасыщен- } \\
\text { ной части) } \\
\text { High (for water- } \\
\text { saturated side) }\end{array}$ \\
\hline $\begin{array}{l}\text { Размер пор } \\
\text { Pore size }\end{array}$ & $\begin{array}{c}\text { Высокая } \\
\text { High }\end{array}$ & $\begin{array}{l}\text { Низкая } \\
\text { Low }\end{array}$ \\
\hline $\begin{array}{c}\text { Подвижность } \\
\text { воды } \\
\text { Water mobility }\end{array}$ & $\begin{array}{c}\text { Высокая } \\
\text { High }\end{array}$ & $\begin{array}{c}\text { Низкая } \\
\text { Low }\end{array}$ \\
\hline $\begin{array}{c}\text { Соленость воды } \\
\text { Water salinity }\end{array}$ & $\begin{array}{l}\text { Нулевая } \\
\text { Null }\end{array}$ & $\begin{array}{c}\text { Высокая } \\
\text { High }\end{array}$ \\
\hline $\begin{array}{c}\text { Вязкость нефти } \\
\text { Oil viscosity }\end{array}$ & $\begin{array}{c}\text { Высокая } \\
\text { High }\end{array}$ & $\begin{array}{l}\text { Нулевая } \\
\text { Null }\end{array}$ \\
\hline $\begin{array}{l}\text { Присутствие } \\
\text { тяжелой нефти } \\
\text { Occurrence of } \\
\text { heavy oil }\end{array}$ & $\begin{array}{c}\text { Высокая } \\
\text { (при неизвестной } \\
\text { общей пористости) } \\
\text { High (for unknown } \\
\text { total porosity) }\end{array}$ & $\begin{array}{c}\text { Высокая } \\
\text { (при известной об- } \\
\text { щей пористости) } \\
\text { High (for known } \\
\text { total porosity) }\end{array}$ \\
\hline $\begin{array}{c}\text { Парамагнитные } \\
\text { примеси } \\
\text { Paramagnetic } \\
\text { impurities } \\
\end{array}$ & $\begin{array}{c}\text { Высокая (осложняет } \\
\text { процесс измерения) } \\
\text { High (complicate } \\
\text { measurement process) }\end{array}$ & $\begin{array}{c}\text { Нулевая } \\
\text { Null }\end{array}$ \\
\hline
\end{tabular}

Таким образом, применение комплекса этих методов позволяет повысить точность определения структуры порового пространства горных пород и реологических свойств пластовых флюидов.

Целью работы является совместная интерпретация данных методов диэлектрической спектроскопии и ЯМР-релаксометрии для определения связи комплексной диэлектрической проницаемости (КДП) и ЯМР-характеристик проб нефти и конденсатов месторождений Восточной и Западной Сибири, характеризующихся разными физико-химическими свойствами, с результатами геохимического анализа.

\section{Методика проведения экспериментов}

При измерении КДП образцов исследуемое вещество помещается в экспериментальную ячейку. Ячейка представляет собой цилиндрический конденсатор с внутренним диаметром внешнего электрода $50 \mathrm{Mм}$, внешним диаметром внутреннего электрода 40 мм и высотой активной области 50 мм, и подключается к измерительному прибору двумя проводами. Измерительным прибором выступает измеритель комплексного импеданса LCR-78105G производства компании GwInstek с диапазоном рабочих частот 0,02-5000 кГц. После получения значений компонент импеданса рассчитываются значения емкости пустой ячейки, а после и ячейки с образцом. По рассчитанным данным определяется значение диэлектрической проницаемости (ДП) на соответствующей частоте $[5,6]$.

По описанной методике определены значения диэлектрической проницаемости 30 образцов нефти и конденсатов. Дополнительно на 6 пробах проведены измерения по методике П.П. Боброва в частотном диапазоне от 20 Гц до 5 ГГц в коаксиальной ячейке [7, 8].

Экспериментальные исследования по определению ЯМР-характеристик проб нефти и конденсатов выполняются на ЯМР-релаксометре «МСТ-05» с величиной индукции магнитного поля 500-530 Гс (0,05 Тл) и рабочей частотой 2,2-2,3 МГц, диапазон измеряемых времён поперечной релаксации $\left(\mathrm{T}_{2}\right)$ от 600 мкс до 10 с. Основным результатом ЯМРизмерения является релаксационная кривая, начальная амплитуда которой соответствует общему водородосодержанию, которое может быть пересчитано в общую ЯМР-пористость. Математическая обработка релаксационной кривой (методом наименьших квадратов с применением регуляризации Тихонова) дает распределение по временам $\mathrm{T}_{2}$, соответствующее в пористой среде распределению пор по размерам, в жидкостях - групповому составу [9-16].

Характеристика физико-химических свойств нефтей и конденсатов изучаемой коллекции проведена по вязкости, плотности, групповому и фракционному составу. Аналитические исследования проводились современными стандартизованными методиками изучения состава и свойств углеводородных (УВ) флюидов [17], а именно: измерение плотности - вибрационным методом [18]; вязкости - с помощью вискозиметров Пинкевича [19]; определение фракционного состава и получение фракций, выкипающих при температурах выше и ниже $200{ }^{\circ} \mathrm{C},-$ простой атмосферной перегонкой с однократным испарением [20]; определение группового состава - методом адсорбционной жидкостной хроматографии (для фракций выше $200{ }^{\circ} \mathrm{C}$ ) и методом ИК-спектроскопии (для фракций ниже $\left.200{ }^{\circ} \mathrm{C}\right)[21]$.

\section{Описание исследуемой коллекции проб нефтей и конденсатов}

Исследованная коллекция представлена поверхностными пробами нефтей (44 пробы) и конденсатов (4 пробы), отобранными из залежей кембрия, венда, рифея месторождений Восточной Сибири; залежей средней, верхней юры, верхнего и нижнего мела месторождений Западной Сибири с диапазона глубин от 1673-1680 до 3639-3659 м, различающихся по своим физико-химическим свойствам. Представительность коллекции отражена в табл. 2.

Комплекс методов, направленных на определение физико-химических свойств нефтей и конденсатов, применен для 29 проб изучаемой коллекции (4 конденсата, 25 нефтей). Для них установлены значения плотности при $20{ }^{\circ} \mathrm{C}$ (29 проб), вязкости при 20 и $60{ }^{\circ} \mathrm{C}$ (26 и 25 проб, соответственно), содержания температурных фракций выше и ниже $200{ }^{\circ} \mathrm{C}$ (24 пробы), содержания метано-нафтеновых (Me-Nn) и нафтеноароматических (Nn-Ar) УВ, смол и асфальтенов в общем составе нефтей и конденсатов (29 проб) и в их температурных фракциях (22 пробы). 
Таблица 2. Представительность исследованной коллекции проб и комплекс выполненных анализов

Table 2. $\quad$ Representativeness of the studied samples collection and a set of analyzes

\begin{tabular}{|c|c|c|c|c|c|}
\hline $\begin{array}{l}\text { № пробы } \\
\text { Probe no. }\end{array}$ & $\begin{array}{l}\text { Месторождение } \\
\text { Field }\end{array}$ & $\begin{array}{l}\text { Тип флюида } \\
\text { Fluid type }\end{array}$ & $\begin{array}{c}\text { Физико-химические свойства } \\
\text { Physical/chemical properties }\end{array}$ & $\begin{array}{l}\text { КДП } \\
\mathrm{CDP}\end{array}$ & $\begin{array}{l}\text { ЯMP } \\
\text { NMR }\end{array}$ \\
\hline 1 & $\begin{array}{l}\text { Новопортовское } \\
\text { Novoportovskoe }\end{array}$ & нефть/oil & + & - & + \\
\hline 2 & $\begin{array}{l}\text { Бованенковское } \\
\text { Bovanenkovskoe }\end{array}$ & нефть/oil & + & - & + \\
\hline 3 & $\begin{array}{l}\text { Новопортовское } \\
\text { Novoportovskoe }\end{array}$ & нефть/oil & + & - & + \\
\hline 4 & $\begin{array}{l}\text { Новопортовское } \\
\text { Novoportovskoe }\end{array}$ & нефть/oil & + & - & + \\
\hline 5 & $\begin{array}{l}\text { Геофизическое } \\
\text { Geophysicheskoe }\end{array}$ & нефть/oil & + & - & + \\
\hline 6 & $\begin{array}{l}\text { Восточно-Мессояхское } \\
\text { Vostochno-Messoykhskoe }\end{array}$ & нефть/oil & + & - & + \\
\hline 7 & Ванкорское/Vankorskoe & нефть/oil & + & - & + \\
\hline 8 & Салымское/Salymskoe & нефть/oil & + & + & + \\
\hline 9 & Правдинское/Pravdinskoe & нефть/oil & + & - & + \\
\hline 10 & Заполярное/Zapolyarnoe & нефть/oil & + & - & + \\
\hline 11 & Правдинское/Pravdinskoe & нефть/oil & + & - & + \\
\hline 12 & Русское/Russkoe & нефть/oil & + & - & + \\
\hline 13 & Ямбургское/Yamburgskoe & нефть/oil & + & - & + \\
\hline 14 & $\begin{array}{l}\text { Западно-Тамбейское } \\
\text { Zapadno-Tambeyskoe }\end{array}$ & нефть/oil & + & + & + \\
\hline 15 & Сузунское/Suzunskoe & нефть/oil & + & - & + \\
\hline 16 & $\begin{array}{l}\text { Восточно-Мессояхское } \\
\text { Vostochno-Messoykhskoe }\end{array}$ & нефть/oil & + & - & + \\
\hline 17 & Салмановское/Salmanovskoe & конденсат/condensate & + & - & + \\
\hline 18 & Салмановское/Salmanovskoe & конденсат/condensate & + & - & + \\
\hline 19 & Етыпурское/Etypurskoe & нефть/oil & + & - & + \\
\hline 20 & Ванъеганское/Vaneganskoe & нефть/oil & + & - & + \\
\hline 21 & Утреннеe/Utrennee & конденсат/condensate & + & + & + \\
\hline 22 & Паяхское/Payakhskoe & нефть/oil & + & + & + \\
\hline 23 & $\begin{array}{l}\text { Восточно-Бованенское } \\
\text { Vostochno-Bovanenkovskoe }\end{array}$ & нефть/oil & + & + & + \\
\hline 24 & Солетское/Soletskoe & конденсат/condensate & + & + & + \\
\hline 25 & Ванкорское/Vankorskoe & нефть/oil & + & + & + \\
\hline 26 & Ярудейское/Yarudeyskoe & нефть/oil & - & + & + \\
\hline 27 & Уренгойское/Urengoyskoe & нефть/oil & + & + & + \\
\hline 28 & $\begin{array}{l}\text { Bерхнечасельское } \\
\text { Verkhnecheselskoe }\end{array}$ & нефть/oil & - & + & + \\
\hline 29 & Кислорское/Kislorskoe & нефть/oil & - & + & + \\
\hline 30 & Лунгорская пл./Lungorskaya pl. & нефть/oil & - & + & + \\
\hline 31 & $\begin{array}{l}\text { Западно-Котухтинское } \\
\text { Zapadno-Kotukhtinskoe }\end{array}$ & нефть/oil & - & + & + \\
\hline 32 & $\begin{array}{l}\text { Северо-Толькинская пл. } \\
\text { Severo-Tolkinskaya pl. }\end{array}$ & нефть/oil & - & + & + \\
\hline 33 & $\begin{array}{l}\text { Мотртынья-Тетеревское } \\
\text { Motrtynya-Teterevskoe }\end{array}$ & нефть/oil & - & + & + \\
\hline 34 & Советское/Sovetskoe & нефть/oil & - & + & + \\
\hline 35 & Кондаковское/Kondakovskoe & нефть/oil & - & + & + \\
\hline 36 & Пихтовая пл./Pikhtovaya pl. & нефть/oil & + & + & + \\
\hline 37 & Первомайское/Pervomayskoe & нефть/oil & - & + & + \\
\hline 38 & Соболиное/Sobolinoe & нефть/oil & - & + & + \\
\hline 39 & Веселовское/Veselovskoe & нефть/oil & - & + & + \\
\hline 40 & $\begin{array}{l}\text { Маччобинская пл. } \\
\text { Machobinskaya pl. }\end{array}$ & нефть/оil & - & + & + \\
\hline 41 & $\begin{array}{l}\text { Верхневелючанская пл. } \\
\text { Verkhnevelyuchinskaya pl. }\end{array}$ & нефть/oil & - & + & + \\
\hline 42 & $\begin{array}{l}\text { Среднеботуобинская пл. } \\
\text { Srednebotuobinskaya pl. }\end{array}$ & нефть/oil & - & + & + \\
\hline 43 & $\begin{array}{l}\text { Моктаконская пл. } \\
\text { Moktakonskaya pl. }\end{array}$ & нефть/oil & - & + & + \\
\hline 44 & $\begin{array}{l}\text { Куюмбинская пл. } \\
\text { Kuyumbinskaya pl. }\end{array}$ & нефть/oil & + & + & + \\
\hline 45 & $\begin{array}{l}\text { Верхнечонская пл. } \\
\text { Verhknechonskaya pl. }\end{array}$ & нефть/oil & - & + & + \\
\hline 46 & Талаканское/Talakanskoe & нефть/оil & - & + & + \\
\hline 47 & $\begin{array}{l}\text { Юрубчено-Тохомское } \\
\text { Yurubcheno-Tokhomskoe }\end{array}$ & нефть/oil & - & + & + \\
\hline 48 & Левобережное/Levoberezhnoe & нефть/oil & + & + & + \\
\hline
\end{tabular}


По значениям плотности пробы коллекции относятся к УВ особо легкого типа (конденсатные пробы № 17, $18,21,24$; нефтяные пробы № 8, 10, 13, 14, 19, 22, 23, 27), легкого типа (нефтяные пробы № 11, 15, 20, 25), среднего (нефтяные пробы № 1, 3, 4, 6, 9), тяжелым (нефтяная проба № 16) и битуминозным (нефтяные пробы № 2, 5, 7, 12, 36) [22]. Диапазон значений плотности: $0,739-0,937 \mathrm{r} / \mathrm{cm}^{3}$. Большая часть проб коллекции (пробы № $6,8,10,11,13,14,17-25,27,48)$ соответствует УВ флюидам незначительной динамической вязкости (при $20^{\circ} \mathrm{C}$ ), пять нефтяных проб (№ 3, 9, 15, $16,44)$ - маловязким, три нефтяные пробы (№ $1,4,5)$ - повышенной вязкости, и одна нефтяная проба (№ 7) высоковязким. При этом динамическая вязкость битуминозных нефтей (№ 2, 12, 36), в соответствии с техническими возможностями лабораторного анализа, определена только при $60{ }^{\circ} \mathrm{C}$, полученные значения позволяют отнести их к высоковязким УВ флюидам.

Конденсаты коллекции закономерно характеризуются наибольшим содержанием бензиновой фракции (до $200{ }^{\circ} \mathrm{C}$ ) - 52-95\%. В составе особо легких нефтяных проб содержание бензиновой фракции в среднем равно $40 \%$, в составе более тяжелых - $22 \%$.

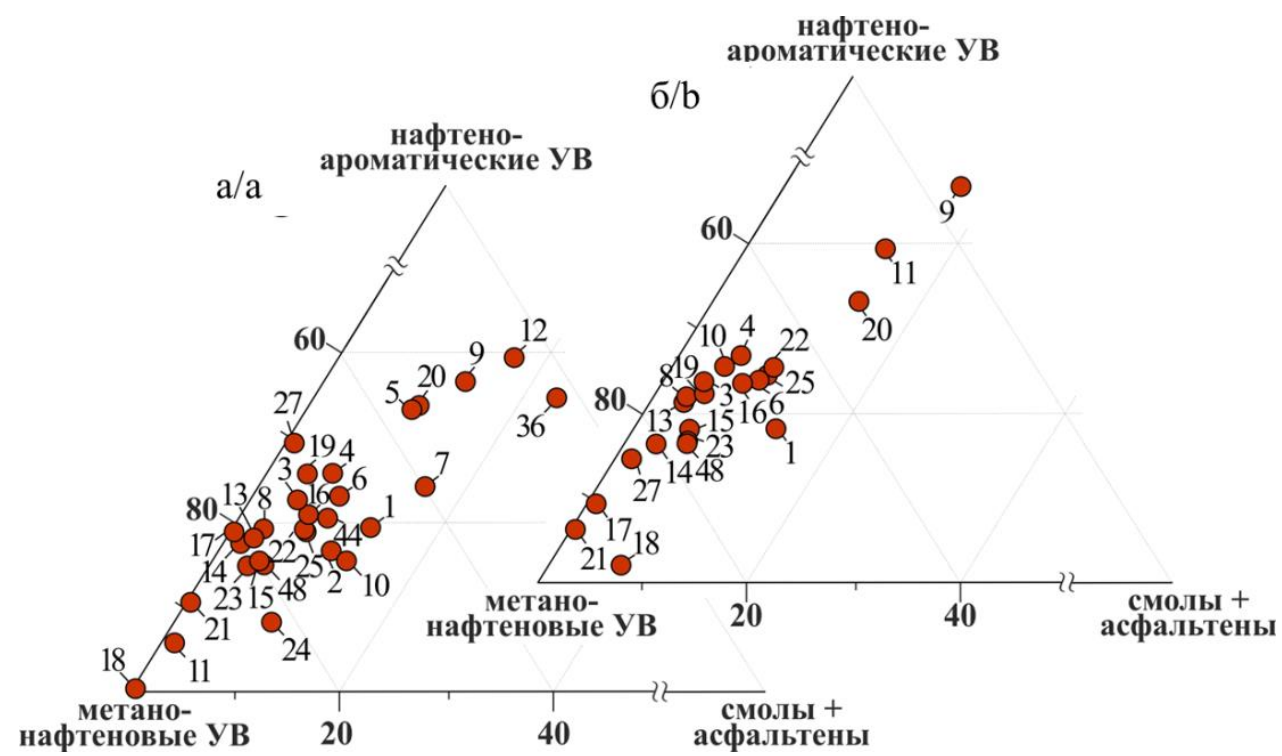

Pис. 1. Групповой состав исследованной коллекции проб: а) на нефть (конденсат); б) на фракцию, выкипаюшую при температуре выше $200{ }^{\circ} \mathrm{C}$

Fig. 1. Group composition of the studied sample collection: a) for oil (condensate); b) for fraction boiling above $200{ }^{\circ} \mathrm{C}$

В групповом составе нефтей и конденсатов коллекции преобладают УВ компоненты (Me-Nn и $\mathrm{Nn}-\mathrm{Ar})-$ более 77 мас. \% на нефть (конденсат). В то же время содержание Me-Nn, Nn-Ar и смолисто-асфальтеновых компонентов меняется в широком диапазоне: $42,2-99,6$ мас. \%; 0,1-39,9 мас. \%; 0,2-22,7 мас. \%, соответственно. Для особо легких и легких проб коллекции характерны в среднем более высокие концентрации насыщенных УВ (78,5 мас. \%), более низкие ароматических УВ $(17,2$ мас. \%) и смолистоасфальтеновых компонентов $(11,6$ мас. \%) (рис. $1, a)$. Наряду с этим более тяжелые нефтяные пробы содержат в среднем 61,2 мас. \% Me-Nn УВ, 27,2 мас. \% Nn-Ar УВ и 11,6 мас. \% смол и асфальтенов (рис. 1, a)

$\mathrm{B}$ составе фракции, выкипающей при температуре выше $200{ }^{\circ} \mathrm{C}$, преобладающую долю имеют Me-Nn УВ (в среднем 71,6 мас. \% на фракцию), меньше $\mathrm{Nn}-\mathrm{Ar}$ УВ (в среднем 21,2 мас. \%), еще меньше смол и асфальтенов (в среднем 7 мас. \%) (рис. 1, б).

Легкокипящая фракция (ниже $200{ }^{\circ} \mathrm{C}$ ) нефтей и конденсатов коллекции преимущественно состоит из Me-Nn УВ (в среднем 86,6 мас. \% на фракцию). Отклоняются от этой закономерности три нефтяные пробы - № 3, 19 и 27, в составе их легкокипящих фракций, несмотря на фактическое преобладание Ме-
Nn УВ (52,1-67,6 мас. \%), сравнительно повышены концентрации Nn-Ar УВ (32,4-47,9 мас. \%).

Комплексная диэлектрическая проницаемость и ЯМР-характеристики проб нефтей и конденсатов

На пробах нефтей и конденсатов выполнены эксперименты по определению диэлектрических (на 30 образцах + 6 повторно) и ЯМР-характеристик (на 48 образцах). Действительная часть КДП (घ') на частоте (f) 1 кГц меняется в диапазоне 2,1-2,89 отн.ед., достигая максимальных значений для проб № 8 и 36 (рис. 2).

На рис. 2 видно, что зависимости действительной части КДП от частоты для трех проб нефти (№ 8,36 и 42) существенно отличаются от зависимостей для остальных проб. У этих образцов наблюдается ярко выраженная релаксация ДП, которая может быть вызвана наличием релаксанта (вода, соль) в составе образца. В пробе № 8 (Салымское месторождение баженовской свиты) содержание солей, вероятно, превышает их содержание в пробах № 36 и 42. Для остальных образцов зависимости имеют схожий вид кривых, отличаются только значениями ДП, которая зависит от группового состава проб нефти и конденсатов (рис. 3). 


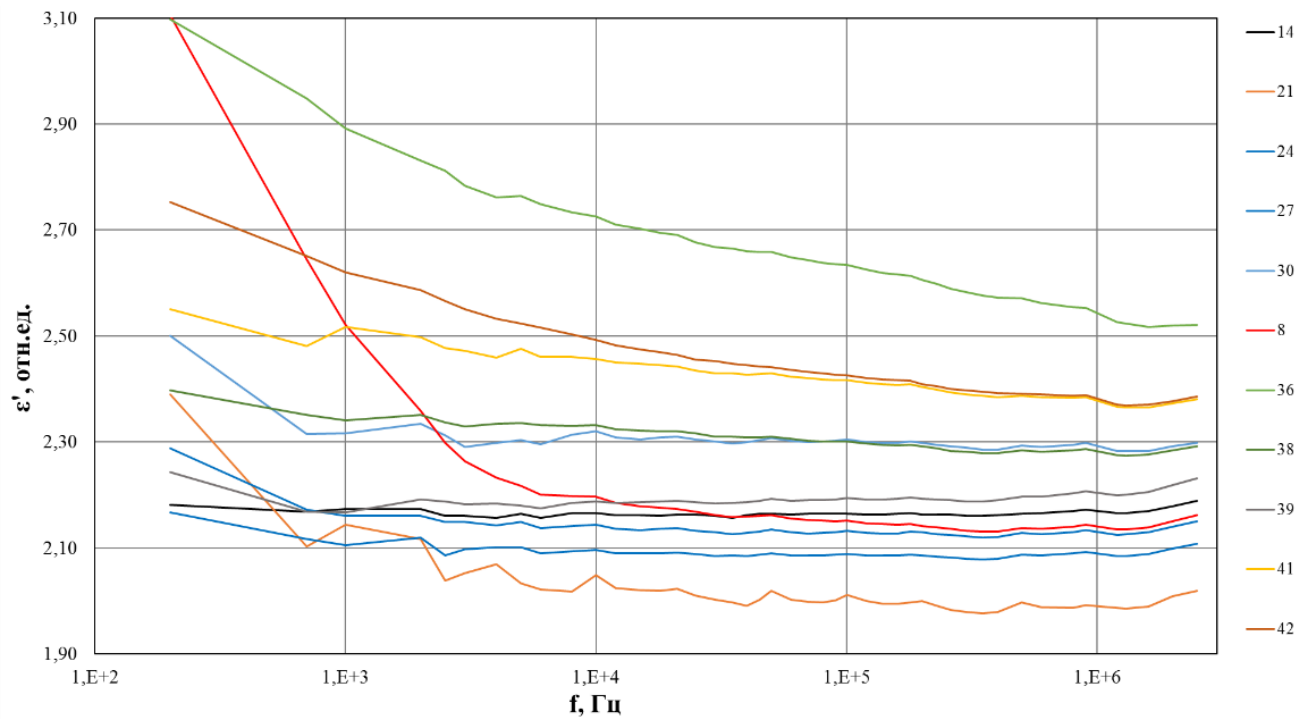

Pис. 2. Зависимость действительной части КДП от частоты

Fig. 2. Dependence of the complex dielectric permittivity $(C D P)$ real part on frequency

• Смолисто-асфальтеновые соединения • Ароматические УВ • Насыщенные УВ

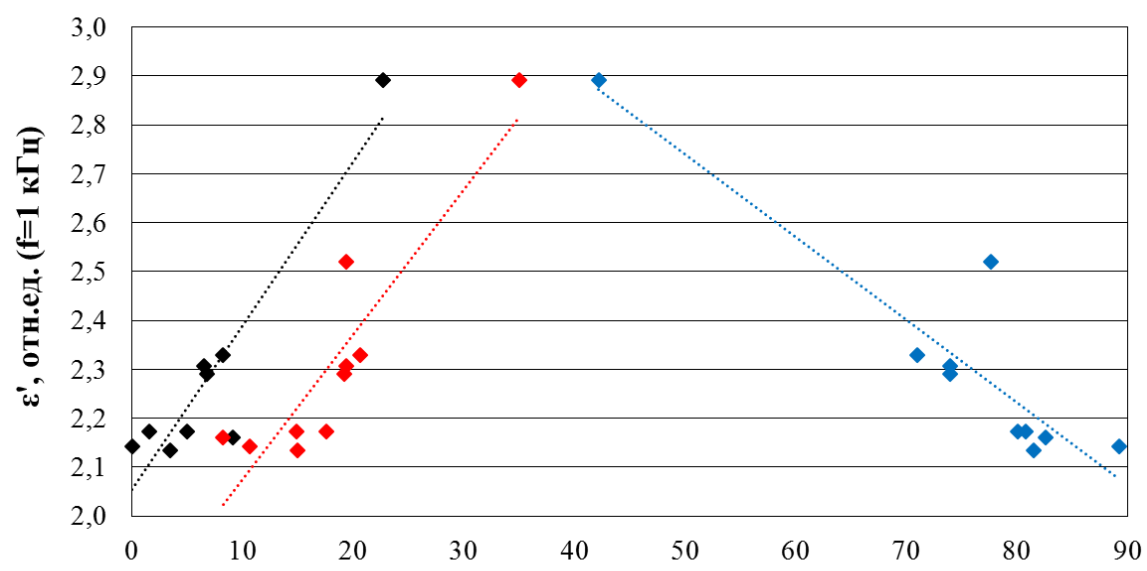

Содержание разных групп соединений в пробе, \%

Рис. 3. Зависимость действительной части КДП от группового состава проб нефтей и конденсатов на частоте 1 кГи

Fig. 3. Dependence of the CDP real part on the group composition of oil and condensate samples at a frequency of $1 \mathrm{kHz}$

На рис. 3 видна линейная зависимость значений КДП от процентного содержания разных групп углеводородных соединений. При увеличении количества смолисто-асфальтеновых и ароматических соединений значения КДП увеличиваются, при этом увеличение насыщенных УВ сопровождается уменьшением значений КДП. Такое поведение можно объяснить тем, что у смолисто-асфальтеновых и ароматических соединений значение КДП на частоте 1 кГц существенно выше, чем у насыщенных.

По данным геохимического анализа и диэлектрической спектроскопии было проведено математическое моделирование значений ДП компонент нефти в отдельности. Используя простую формулу смешивания (сумма произведений объемной доли компоненты на значение ДП), установлено, что значение КДП для смолисто-асфальтеновых соединений составляет $\approx 3,5$ отн. ед., для ароматических соединений $-2,9$ отн. ед. и для насыщенных УВ - порядка 1,9 отн. ед. Полу- ченные результаты подтверждают гипотезу, описанную выше.

По ЯМР-данным пробы характеризуются широкими диапазонами времен $\mathrm{T}_{2}$ (от 11 до 1500 мс со средним значением 310 мс) и водородосодержания (от 60 до 98 \%). Спектры по временам поперечной релаксации также значительно отличаются по амплитуде, ширине и положению на оси $\mathrm{T}_{2}$ (рис. 4).

По спектрам видно, что из представленных на графике проб проба № 36 характеризуется наименьшими значениями среднего логарифмического времени поперечной релаксации $\left(\mathrm{T}_{2}^{\mathrm{LM}}-\right.$ среднее значение времени поперечной релаксации по спектру с учетом вклада каждой компоненты со своим значением $\mathrm{T}_{2}$, для пробы

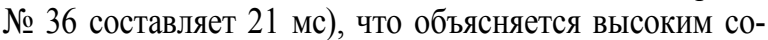
держанием смолисто-асфальтеновых соединений (>20\%). Ее вязкость из изученных образцов самая высокая: при $60{ }^{\circ} \mathrm{C}$ она составляет $102,8 \mathrm{~mm}^{2} / \mathrm{c}$, а плотность равна 0,9103 г/см ${ }^{3}$. При этом можно отме- 
тить, что самой легкой является проба № 21 с вязкостью $0,77 \mathrm{mм}^{2} / \mathrm{c}$ и плотностью $0,7393 \mathrm{r} / \mathrm{cm}^{3}$. Содержание смолисто-асфальтеновых соединений в пробе $<1 \%$, что в наибольшей степени определяет значения $\mathrm{T}_{2}^{\mathrm{LM}}$ этой пробы больше $1000 \mathrm{Mc}$.
Как и в случае диэлектрических свойств, ЯМРхарактеристики (в частности $\mathrm{T}_{2}^{\mathrm{LM}}$ ) напрямую зависят от группового состава исследуемых проб. Рассмотрим зависимость времени поперечной релаксации от группового состава проб нефтей и конденсатов (рис. 5).

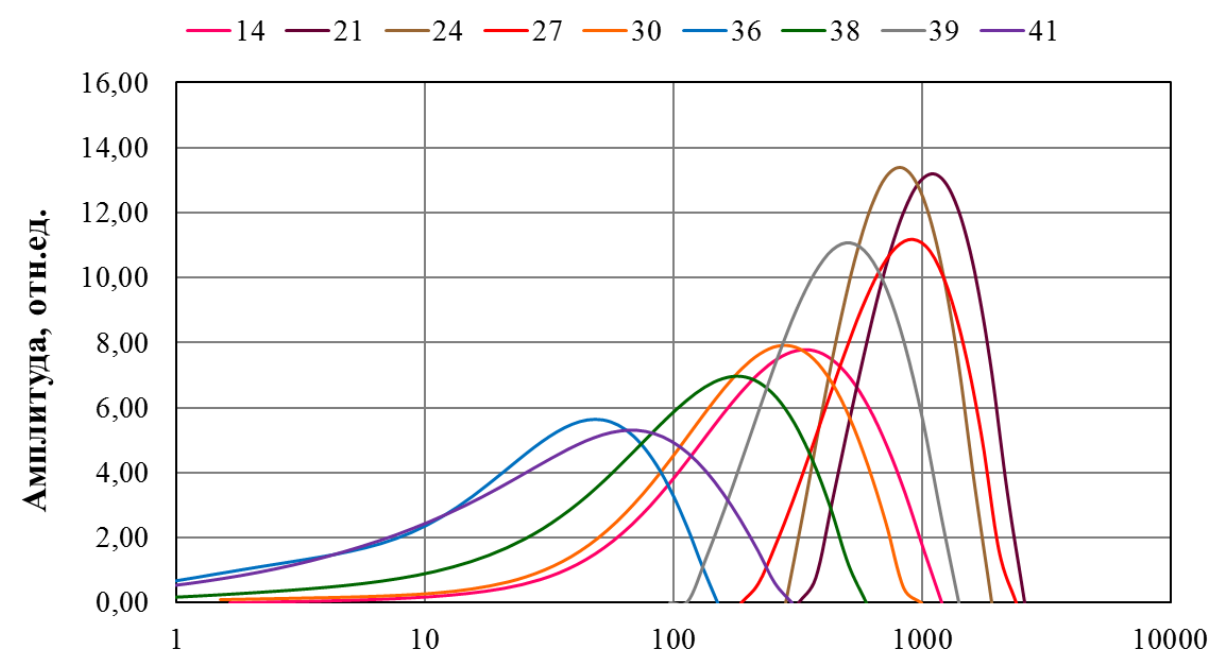

Время поперечной релаксации, мс

Puc. 4. Спектры времен поперечной релаксаиии для ряда проб исследуемой коллекции

Fig. 4. Transverse relaxation times spectra for several studied collection samples

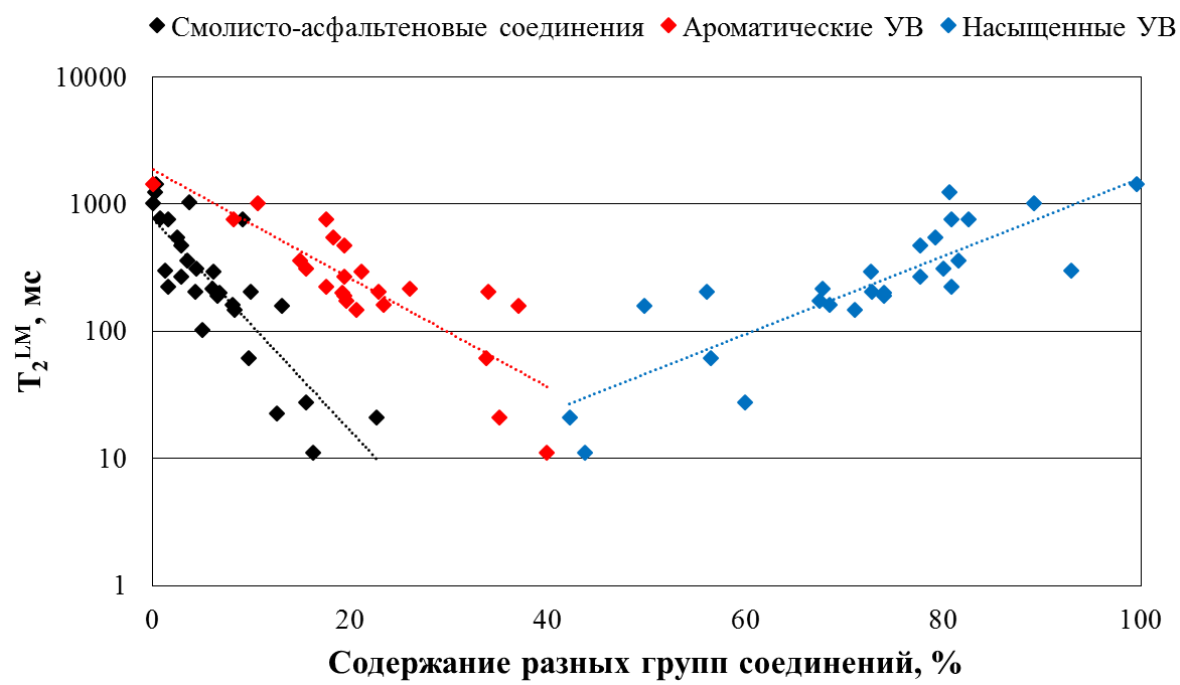

Рис. 5. Зависимость времени поперечной релаксаиии от группового состава проб нефтей и конденсатов

Fig. 5. Dependence of the transverse relaxation times on the group composition of oil and condensate samples

На рис. 5 наблюдаются зависимости обратные зависимостям, представленным на рис. 3. Увеличение содержания смолисто-асфальтеновых и ароматических соединений приводит к уменьшению значений $\mathrm{T}_{2}^{\mathrm{LM}}$, в то время как увеличение доли насыщенных УВ увеличивает значения $\mathrm{T}_{2}^{\mathrm{LM}}$. Это объясняется тем, что наличие смолисто-асфальтеновых соединений затрудняет свободное движение молекул в образце и приводит к ускорению релаксационных процессов и существенному уменьшению времен поперечной релаксации, так как они представляют собой большие агрегаты-кластеры со сложной надмолекулярной структурой [23]. Можно сделать вывод, что КДП имеет обратную зависимость от времени $\mathrm{T}_{2}^{\mathrm{LM}}$. Чем больше значения $\mathrm{T}_{2}^{\mathrm{LM}}$ пробы нефти/конденсата, тем выше содержание в ней насыщенных УВ и ниже смолисто-асфальтеновых и ароматических соединений, а реальная часть КДП будет меньше (рис. 6).

В рамках настоящей работы также был определен групповой состав всех проб коллекции по их ЯМРхарактеристикам путем разделения на интервалы $\mathrm{T}_{2}$, характерные для каждой из групп соединений. При температуре $25{ }^{\circ} \mathrm{C}$ времена поперечной релаксации $\mathrm{T}_{2}$ смолисто-асфальтеновых соединений не превышают 30 мс, ароматических соединений - 500 мс, насыщенных УВ - 1200 мс (данные получены по результатам ЯМР-измерений исследуемых 48 проб нефти). 
Оцененный при помощи метода ЯМРрелаксометрии групповой состав согласуется с результатами стандартного геохимического анализа, расхождение при комнатной температуре составляет не более $5 \%$ (рис. 7).

Установить более детальные границы времен $\mathrm{T}_{2}$ для каждой группы УВ-соединений пока не удается. Смолисто-асфальтеновые соединения определяются с высокой точностью, значения $\mathrm{T}_{2}$ для них составляют
0,1-30 мс, в то время как значения $\mathrm{T}_{2}$ для ароматических соединений и насыщенных УВ сильно перекрываются. Это не позволяет выделить каждую группу отдельно. В этом направлении ведется работа, связанная с расширением коллекции исследуемых образцов нефти, проведением дополнительных экспериментальных исследований и усовершенствованием методики обработки исходного ЯМР-сигнала.

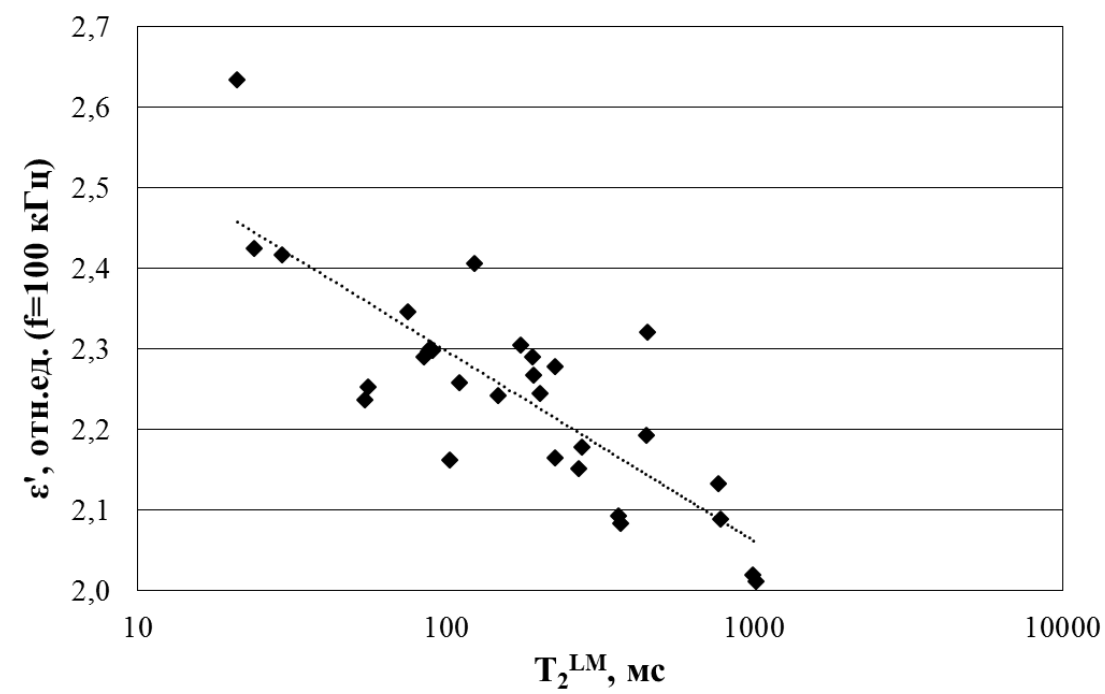

Pис. 6. Зависимость действительной части КДП от среднего логарифмического времени поперечной релаксации на частоте $100 \kappa \Gamma \mathrm{u}$

Fig. 6. Dependence of the CDP real part on the logarithmic mean of transverse relaxation times at a frequency of $100 \mathrm{kHz}$

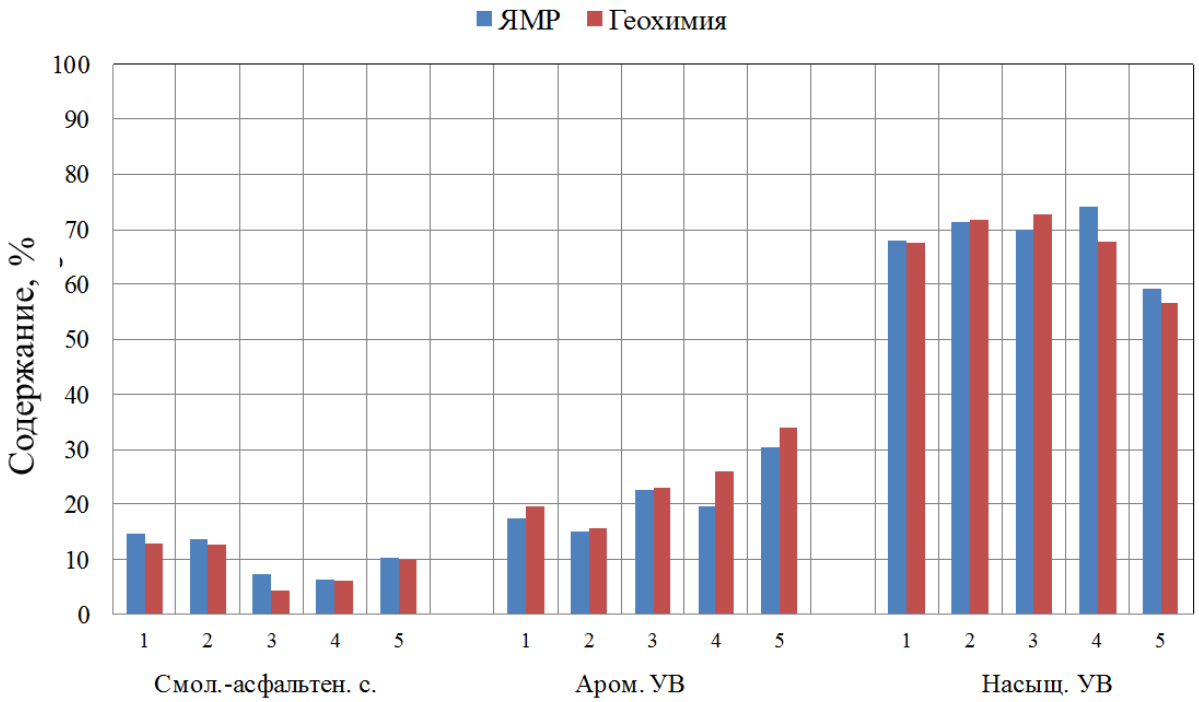

Pис. 7. Группой состав проб нефти, полученный по данным ЯМР-релаксометрии и геохимического анализа

Fig. 7. Group composition of oil samples obtained from the NMR-relaxometry and geochemical analysis data

\section{Заключение}

В рамках выполненного исследования экспериментально установлено, что совместная интерпретация данных методов диэлектрической спектроскопии и ЯМР-релаксометрии позволяет получить дополнительную информацию о физико-химических свойствах нефти. Оба метода являются очень чувствительными к наличию и содержанию смолисто-асфальтеновых со- единений: увеличение их доли в составе пробы нефти приводит к существенному уменьшению времен поперечной релаксации и значительному увеличению значений комплексной диэлектрической проницаемости. Наличие смолисто-асфальтеновых соединений затрудняет свободное движение молекул в образце, что приводит к увеличению вязкости, ускорению релаксационных процессов и существенному уменьшению времен поперечной релаксации. 
Групповой состав проб нефти, определенный при температуре $25^{\circ} \mathrm{C}$ по данным ЯМР-метода, согласуется с результатами геохимического анализа с точностью до 5 \%. При повышении температуры измерения точность определения группового состава уменьшается. Установить точные границы времен $\mathrm{T}_{2}$ для каждой группы углеводородных соединений не удается, поскольку времена поперечной релаксации аромати-

\section{СПИСОК ЛИТЕРАТУРЫ}

1. Аксельрод С.М. Новые тенденции в диэлектрическом каротаже (по материалам зарубежной печати) // Каротажник. 2012. - № 4 (214). - С. 78-112.

2. Связь комплексной диэлектрической проницаемости нефти с ее физико-химическими свойствами и ЯМР-характеристиками / А.А. Мезин, М.Й. Шумскайте, Н.А. Голиков, А.И. Бурухина // Геофизические технологии. - 2019. - № 4. - С. 24-34. URL: https://www.rjgt.ru/jour/article/view/83 (дата обращения 15.07.2020).

3. Hysteresis of the NMR response and the complex relative permittivity of the quartz granules powders and solid sandstones during the water imbibition and drainage / A.S. Lapina, P.P. Bobrov, N.A. Golikov, A.V. Repin, M.Y. Shumskayte // Measurement Science and Technology. - 2017. - T. 28. - № 1. P. 014007-014007.

4. Toumelin E., Torres-Verdin C., Bona N. Improving Petrophysical Interpretation with Wide-Band Electromagnetic Measurements // SPE Journal. - June 2008. - P. 205-215.

5. The magneto-dielectric anisotropy effect in the oil-based ferrofluid / Š. Hardoň, J. Kúdelcík, E. Jahoda, M. Kúdelcikova // International Journal of Thermophysics. - 2019. - T. 40. - № 2. - 11 c.

6. Singh S.P., Chandel V.S., Manohar R. Dielectric study of Clove oil // Journal of Ayurveda and integrative medicine. - 2018. V. 9. - № 1. - P. 53-56.

7. Бобров П.П., Кондратьева (Родионова) О.В., Репин А.В. Измерение комплексной диэлектрической проницаемости образца в одной ячейке от десятков герц до единиц гигагерц // Известия высших учебных заведений. Физика. - 2012. - Т. 55 . № 8/3. - C. $23-26$.

8. Способ измерения комплексной диэлектрической проницаемости жидких и сыпучих веществ: пат. Рос. Федерация, № 2012119574, заявл. 14.11.2013; опубл. 10.03.2014, Бюл. № 7. $15 \mathrm{c}$.

9. Лабораторное изучение жидкостей, выносимых из скважин, методом ЯМР-релаксометрии / М.Й. Шумскайте, В.Н. Глинских В.Н., С.Б. Бортникова, А.Н. Харитонов, В.С. Пермяков // Известия Томского политехнического университета. Инжиниринг георесурсов. - 2017. - Т. 328. - № 2. - С. 59-66.

10. Применение ядерного магнитного резонанса-релаксометрии для экспресс-исследования реологических свойств и группового состава нефти и конденсата / А.Х. Тураханов, В.Н. Глинских, В.А. Каширцев, Е.А. Фурсенко, М.Й. Шумскайте // Нефтегазовая геология. Теория и практика. - 2017. - Т. 12. - ческих и насыщенных углеводородов сильно перекрываются.

Работа выполнена в рамках проекта фундаментальных научных исследований № 0266-2019-0006 «Разработка методик оиенки ресурсов, разведки и подсчета запасов залежей трудноизвлекаемой нефти в углеродистых карбонатно-глинисто-кремнистых, карбонатных и засолоненных песчаных коллекторах».

№ 3. - C. 1-15. URL: http://www.ngtp.ru/rub/2017/29_2017.html (дата обращения 15.07.2020).

11. Carr H.Y., Purcell E.M. Effects of diffusion on free precession in nuclear magnetic resonance experiments // Physical review. 1954. - V. 94. - P. 630-638.

12. Coates J., Xiao L., Prammer M. NMR logging. Principles and applications. - Houston: Halliburton Energy Services, 1999. $342 \mathrm{p}$.

13. Dunn K.J., Bergman D.J., LaTorracca G.A. Nuclear magnetic resonance. Petrophysical and logging application. - London: PERGAMON, 2002. - $294 \mathrm{p}$

14. Автоматизированный малогабаритный релаксометр ядерного магнитного резонанса / З.Ш. Идиятуллин, А.Н. Темников, О.В. Рыбаков, Р.С. Кашаев // Приборы и техника эксперимента. 1992. - № 5. - C. 237-238.

15. Кашаев Р.С. Структурно-динамический анализ нефтяных дисперсных систем. - Казань: Грандан, 1999. - 129 с.

16. Кашаев Р.С. Изучение динамики структурного упорядочения в нефтяных дисперсных системах методом ЯМР // Нефтехимия. -2003 . - Т. 43. - № 2. - С. 143-150.

17. Chemical fingerprints of crude oils and petroleum products / C. Yang, C.E. Brown, B. Hollebone, Z. Yang, P. Lambert, B. Fieldhouse, M. Landriault, Z. Wang. - Canada: Environ, 2017. $-465 \mathrm{p}$

18. ГОСТ Р 57037-2016. Нефтепродукты. Определение плотности, относительной плотности и плотности в градусах API цифровым плотномером. - М.: Стандартинформ, 2016. - 14 с.

19. ГОСТ 33-2000. Нефтепродукты. Прозрачные и непрозрачные жидкости. Определение кинематической вязкости и расчет динамической вязкости. - М.: Изд-во стандартов, 2008. - 20 с

20. ГОСТ 2177-99. Нефтепродукты. Метод определения фракционного состава. - М.: Изд-во стандартов, 2006. - 24 с.

21. Современные методы исследования нефтей: справочнометодическое пособие / под ред. А.И. Богомолова, М.Б. Темянко, Л.И. Хотынцевой. - Л.: Недра, 1984. - 431 с.

22. Методические рекомендации по применению классификации запасов и ресурсов нефти и горючих газов / под ред. С.Е. Донского. - М.: Минприроды России, 2016. - 32 с.

23. Jones M., Taylor S.E. NMR relaxometry and diffusometry in characterizing structural, interfacial and colloidal properties of heavy oils and oil sands // Advances in Colloid and Interface Science. -2015 . - V. 224. - P. 33-45.

Поступила: 21.07.2020 2.

Информация об авторах

Мезин A.A., младший научный сотрудник Института нефтегазовой геологии и геофизики им. А.А. Трофимука $\mathrm{CO}$ PAH

Шумскайте М.Й., кандидат технических наук, старший научный сотрудник Института нефтегазовой геологии и геофизики им. А.А. Трофимука СО РАН.

Чернова E.C., магистрант Новосибирского государственного университета.

Бурухина А.И., младший научный сотрудник Института нефтегазовой геологии и геофизики им. А.А. Трофимука СО РАН. 
UDK $537.8+550.84$

\title{
PHYSICAL/CHEMICAL PROPERTIES OF OIL FROM EASTERN AND WESTERN SIBERIA DEPOSITS: INTEGRATED STUDY BY DIELECTRIC SPECTROSCOPY AND NMR RELAXOMETRY METHODS
}

\author{
Andrey A. Mezin 1 , \\ MezinAA@ipgg.sbras.ru
}

Mariya Y. Shumskayte ${ }^{1}$, ShumskaiteMl@ipgg.sbras.ru

Elena S. Chernova², ellenchernova@yandex.ru

\author{
Alexandra I. Burukhina ${ }^{1}$, \\ BurukhinaAl@ipgg.sbras.ru \\ 1 Trofimuk Institute of Petroleum Geology and Geophysics of Siberian Branch Russian Academy of Sciences, \\ 3, Koptyug avenue, Novosibirsk, 630090, Russia. \\ 2 Novosibirsk State University, \\ 1, Pirogov street, Novosibirsk, 630090, Russia.
}

The relevance of the research is caused by the increasing interest in an integrated interpretation of several methods data to determining the petrophysical and physical/chemical properties of rocks and intraformational fluids. The physical/chemical properties of oil are determined by a complex of data methods of dielectric spectroscopy, NMR relaxometry and geochemical analysis. The results of these methods are complemented each other, since they differ in different sensitivity to some characteristics of the rock and its saturating fluid.

The main aim of the research is the sequential interpretation of dielectric spectroscopy and NMR relaxometry methods to determine the group composition and physical/chemical properties of oil samples, comparison of the obtained results with the results of geochemical analysis.

Objects: oil and condensate samples from Eastern and Western Siberia deposits characterized by different physical/chemical properties. Methods: laboratory methods of dielectric spectroscopy aimed at determining the complex dielectric constant; NMR relaxometry which allows assessing the group analysis of studied fluid; standard geochemical methods including determination of physical/chemical properties, fractional and group chemical composition of oil.

Results. 48 samples of oils and condensates from fields in Eastern and Western Siberia have been studied. The values were established for 29 samples: density at $20^{\circ} \mathrm{C}$, viscosity at 20 and $60^{\circ} \mathrm{C}$, content of temperature fractions above and below $200{ }^{\circ} \mathrm{C}$, content of methanenaphthenic and naphthenic-aromatic hydrocarbons, resins and asphaltenes. The dependence of the dielectric constant and the transverse relaxation time on the content of different hydrocarbon compounds groups was experimentally established, which showed a high sensitivity of the methods used in this work to the content of resinous-asphaltene compounds. Increasing their proportion in the composition of an oil sample leads to a significant decrease in the transverse relaxation times and a significant increase in the values of the dielectric constant. The NMR data was used to determine the group composition of oil samples, which is consistent with the results of geochemical analysis with an accuracy of $5 \%$ at a temperature of $25^{\circ} \mathrm{C}$. Since the transverse relaxation times of aromatic compounds and saturated hydrocarbons characterized by high overlap, this does not allow us to establish in more detail the boundary transverse relaxation times for each group of hydrocarbon compounds.

Key words:

Group analysis, dielectric permittivity, relaxation characteristics, rheological properties of oils, sequential interpretation.

The research was carried out within the project of fundamental scientific researches no. 0266-2019-0006 «Development of techniques for assessing resources, exploration and estimation of reserves of unconventional oil in carbon, carbonate-argillaceoussilica, carbonate and saline sandy reservoirs».

\section{REFERENCES}

1. Akselrod S.M. Novye tendentsii v dielektricheskom karotazhe (po materialam zarubezhnoy pechati) [New trends in dielectric logging (based on materials from foreign press)]. Karotazhnik, 2012, no. 4 (214), pp. 78-112.

2. Mezin A.A., Shumskayte M.Y., Golikov N.A., Buruhina A.I. Relation of integrated dielectric permeability of oil with its physical and chemical properties and NMR characteristics. Russian Journal of Geophysical Technologies, 2019, no. 4, pp. 24-34. In Rus.

3. Lapina A.S., Bobrov P.P., Golikov N.A., Repin A.V., Shumskayte M.Y. Hysteresis of the NMR response and the complex relative permittivity of the quartz granules powders and solid sandstones during the water imbibition and drainage. Measurement Science and Technology, 2017, vol. 28, no. 1, pp. 014007-014007.
4. Toumelin E., Torres-Verdin C., Bona N. Improving Petrophysical Interpretation with Wide-Band Electromagnetic Measurements. SPE Journal, June 2008, pp. 205-215.

5. Hardoň Š., Kúdelcík J., Jahoda E., Kúdelcikova M. The magnetodielectric anisotropy effect in the oil-based ferrofluid. International Journal of Thermophysics, 2019, vol. 40, no. 2, 11 p.

6. Singh S.P., Chandel V.S., Manohar R. Dielectric study of Clove oil. Journal of Ayurveda and integrative medicine, 2018, vol. 9, no. 1, pp. 53-56.

7. Bobrov P.P., Kondrateva (Rodionova) O.V., Repin A.V. Izmerenie kompleksnoy dielektricheskoy pronictsaemosti obraztsa v odnoy yacheyke ot desyatkov gerts do edinits gigagerts [Measurement of the complex dielectric constant of a sample in one cell from tens of hertz to units of gigahertz]. Izvestiya vysshikh uchebnykh zavedeniy. Fizika, 2012, vol. 55, no. 8/3, pp. 23-26. 
8. Bobrov P.P., Kondrateva (Rodionova) O.V., Repin A.V. Sposob izmereniya kompleksnoy dielektricheskoy pronitsaemosti zhidkikh $i$ sypuchikh veshhestv [Method for measuring the complex dielectric constant of liquid and bulk substances]. Patent RF, no. 2012119574, 2014.

9. Shumskayte M.Y., Glinskikh V.N., Bortnikova S.B., Haritonov A.N., Permyakov V.S. NMR-relaxometry laboratory study of fluids taken from boreholes. Bulletin of the Tomsk Polytechnic University, Geo Assets Engineering, 2017, vol. 328, no. 2. pp. 59-66. In Rus.

10. Turakhanov A.H., Glinskikh V.N., Khashirtsev V.A., Fursenko E.A., Shumskayte M.Y. The application of the nuclear magnet ic resonance relaxometry method to express-study of rheological properties and composition of oil and gas condensate. Neftegazovaya geologijya. Teoriya i praktika, 2017, vol. 12, no. 3 , pp. 1-15. In Rus.

11. Carr H.Y., Purcell E.M. Effects of diffusion on free precession in nuclear magnetic resonance experiments. Physical review, 1954 vol. 94, pp. 630-638.

12. Coates J., Xiao L., Prammer M. NMR logging. Principles and applications. Houston, Halliburton Energy Services, 1999. 342 p.

13. Dunn K.J., Bergman D.J., LaTorracca G.A. Nuclear magnetic resonance. Petrophysical and logging application. London, PERGAMON, 2002. $294 \mathrm{p}$.

14. Idiyatullin Z.Sh., Temnikov A.N., Rybakov O.V., Kashaev R.S. Avtomatizirovanny malogabaritny relaksometr yadernogo magnitnogo rezonansa [Automated small-sized nuclear magnetic resonance relaxometer]. Pribory i tekhnika eksperimenta, 1992, no. 5, pp. 237-238.

15. Strukturno-dinamichskiy analiz neftyanykh dispersnykh sistem [Structural-dynamic analysis of oil dispersed systems]. Ed. by R.S. Kashaev. Kazan, Grandan Publ., 1999. 129 p.

16. Kashaev R.S. Izuchenie dinamiki strukturnogo uporyadocheniya $v$ neftyanykh dispersnykh sistemakh metodom YaMR [Study of the dynamics of structural ordering in petroleum dispersed systems by NMR]. Neftekhimiya, 2003, vol. 43, no. 2, pp. 143-150.

17. Yang C., Brown C.E., Hollebone B., Yang Z., Lambert P., Fieldhouse B., Landriault M., Wang Z. Chemical fingerprints of crude oils and petroleum products. Canada, Environ, 2017. 465 p.

18. GOST 57037-2016. Nefteprodukty. Opredelenie plotnosti, otnositelnoy plotnosti $i$ plotnosti $v$ gradusakh API tsifrovym plotnomerom [State Standard 57037-2016. Petroleum products. Determination of density, relative density and API gravity with a digital density meter]. Moscow, StandartInform Publ., 2016. 14 p.

19. GOST 33-2000. Nefteprodukty. Prozrachnye $i$ neprozrachnye zhidkosti. Opredelenie kinematicheskoy vyazkosti $i$ raschet dinamicheskoy vjazkosti [State Standard 33-2000. Petroleum products. Transparent and opaque liquids. Determination of kinematic viscosity and calculation of dynamic viscosity]. Moscow, Publishing of standards, $2008.20 \mathrm{p}$.

20. GOST 2177-99. Nefteprodukty. Metod opredeleniya fraktsionnogo sostava [State Standard 2177-99. Petroleum products. Method for determining fractional composition]. Moscow, Publishing of standards, 2006. $24 \mathrm{p}$.

21. Sovremennye metody issledovaniya neftey: spravochnometodicheskoe posobie [Modern methods of oil research: reference and methodological manual]. Eds. A.I. Bogomolov, M.B. Temyanko, L I. Khotyntseva. Leningrad, Nedra Publ., 1984. 431 p.

22. Metodicheskie rekomendatsii po primeneniyu klassifikatsii zapasov i resursov nefti i goryuchikh gazov [Guidelines for the application of the classification of reserves and resources of oil and combustible gases]. Ed by. S.E. Donskoy. Moscow, Minpriridy Rossii Publ., 2016. 32 p.

23. Jones M., Taylor S.E. NMR relaxometry and diffusometry in characterizing structural, interfacial and colloidal properties of heavy oils and oil sands. Advances in Colloid and Interface Science, 2015, vol. 224, pp. 33-45.

Received: 21 July 2020.

\section{Information about the authors}

Andrey A. Mezin, junior researcher, Trofimuk Institute of Petroleum Geology and Geophysics of Siberian Branch Russian Academy of Sciences.

Mariya Y. Shumskayte, Cand. Sc., senior researcher, Trofimuk Institute of Petroleum Geology and Geophysics of Siberian Branch Russian Academy of Sciences.

Elena S. Chernova, postgraduate student, Novosibirsk State University.

Alexandra I. Burukhina, junior researcher, Trofimuk Institute of Petroleum Geology and Geophysics of Siberian Branch Russian Academy of Sciences. 